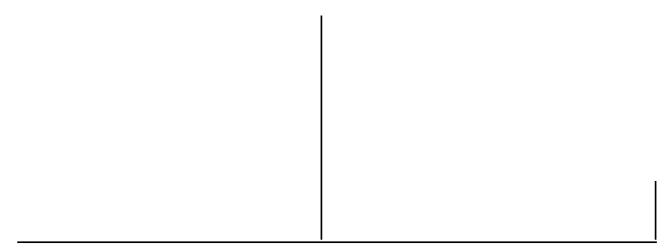

Rev. Latinoam. Psicopat. Fund., VIII, 2, 289-302

\title{
A construção do conceito de neurose (II) Nosologia e neurose*
}

Jorge J. Saurí

O surgimento da idéia de "enfermidade nervosa" proporcionou à psiquiatria do Iluminismo a possibilidade de desenvolver-se numa direção mais concreta e positiva. Não obstante, o campo ainda era difuso, se bem que a obra dos nosólogos ia organizando e discriminando afecções com perfis mais claros. A intenção de levar tal clareza para o terreno das enfermidades nervosas levou W. Cullen a agrupar esses transtornos na classe "neurose". Utilizou-se para isso do procedimento nosológico em voga na época.

Palavras-chave: História da psiquiatria, nosologia, neurose

* Este texto foi publicado com o título "Nosologia e neurose" em Acta Psiq. Psicol. de América latina (1995) 41, 104. Sua tradução do francês, "Nosologie et névrose" foi publicada em Information psychiatrique (1995) 72, 9, 895.

Tradução de Dirceu Scali Jr. e Edgard Murano Filho, para o português. 


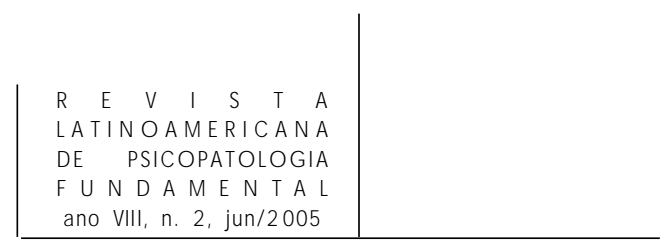

Dois retratos conhecidos, executados com quase um século de diferença entre um e outro, põem às claras tantas outras modalidades das redes epistêmicas da urdidura de crenças naturalista. Em um deles, pintado por volta de 1530, Pontorno representou a duquesa de Urbino de três quartos de perfil, sentada em uma cadeira, com um cãozinho na saia e olhando para a frente. Em sua composição, onde predomina um tratamento racional, o artista inseriu a imagem em um "contexto matematizado", destacando a figura sobre um fundo construído com dois tecidos de parede geometricamente dispostos emoldurando outro de cor mais clara. Pontorno, acentuando o ordenamento das imagens, usou fundos ressaltados e eliminou as diferenças espontâneas, substituindo-as por outras artificiais, pois queria que sua obra exemplificasse e veiculasse a importância da Razão. A vestimenta da duquesa, de ar geométrico de acordo com o fundo - ombros avolumados, vestido vermelho, verde e branco etc. - dá a seu retrato um valor demonstrativo, mostrando como se pensavam a si mesmos os poderosos de então, defensores da Ordem Ideal da Natureza que Galileu dirá estar inscrita em signos matemáticos. Além de representar uma duquesa, a obra é uma metáfora plástica do poder da Razão. Como ocorre em toda urdidura, a arte antecipou as crenças que sustentaram o paradigma newtoniano e a concepção do tipo racional de "espírito ilustrado".

Cem anos depois, ao retratar um bêbado, Franz Hals dá importância à vertente mecânica da Razão, desfeita a referência geométrica, valoriza as cores e desloca a importância dada ao desenho, pois representa outro tipo de homem. Por este motivo se apóia no valor das cores - a cor metaforiza as sensações reduzindo a universalidade da imagem - fazendo de seus ciganos e bêbados representados, seres individuais. A pretensão de universalidade de Pontormo é então substituída pelo convite a demorar-se no representado, propondo a exploração da interioridade. Estamos agora ante a versão da ordem da Natureza descoberta pela "alma sensível". 


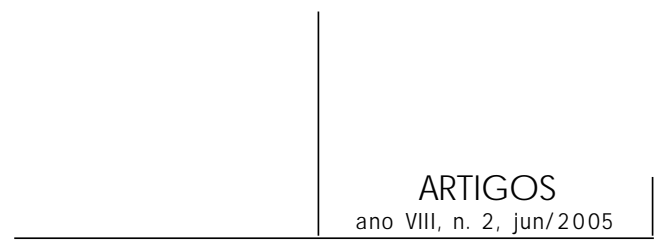

E se na época de Newton buscou-se descobrir leis para explicar a atração dos corpos e demonstrar a existência da força da gravidade, o estudo dos avatares da sensibilidade produziu um efeito análogo, dando ênfase ao empirismo da interioridade. Ambas concepções, a do homem racional e a da "alma sensível", versões de um mesmo homem ilustrado, foram os pilares para a construção da idéia de neurose.

A ilustração, recordemos, aceitava que o comportamento era correto se por respeitar a Ordem prescrita pelo Poder de plantão se adaptava às normas vigentes. A proposta generalizada cuius régio, eius religiu, no século XVI, com os anos havia gerado a figura do "déspota esclarecido", capaz de proclamar leis protetoras do ordenamento social, de observância obrigatória. Tanto as afirmações de Kant sobre o imperativo moral para alcançar a felicidade, como, em outro nível, a admiração de Voltaire por Federico II da Prússia, ajustaram-se a essas propostas, se bem aceitáveis teoricamente, eram inaplicáveis na prática. Essa mesma discordância entre teoria e prática existia no campo científico, área na qual o médico da época das Luzes, aspirante a alcançar as idéias claras, procurou conhecer a ordem natural que supunha o adoecer. A conseqüência dessa ruptura era causar um sofrimento corrigível mediante o restabelecimento do exercício da Razão. E como as idéias vigentes em um dado momento estão em estreita relação com o vocabulário que as expressa, a linguagem médica povoou-se com uma profusão de termos e comparações - relógio, roda, engrenagens... etc. remetentes a concreções do ideal matematizante. Para o homem racional - de Foe, Swiff, d'Holbach, Voltaire, D'Alembert... - atento ao funcionamento da res extensa, a ordem era uma distribuição natural hierárquica objetivável graças à observação e à análise utilizando o paradigma newtoniano para explicar o movimento. Em aparente oposição, para o outro tipo humano, a "alma sensível", - Richardson, Rousseau, Diderot etc. - a ordem foi a disposição dos diversos elementos da Natureza, e sem deixar de lado o objetivo explicativo - a pergunta básica naturalista era "como" são as coisas - valorizou a utilidade da sensibilidade para mergulhar em sua interioridade, o qual se traduziu, na prática, na redação de memórias, diários íntimos e auto-retratos. No entanto, não existiu antagonismo, pois ambos tipos - o racional e o sensitivo - postulavam a necessidade de delimitar melhor os conhecimentos procedendo a seu ordenamento distributivo e hierárquico. A colocação de algo em relação a outra coisa - à autoridade, ao poder etc. - era como um procedimento ordenador e os médicos usaram desse critério para lançar luz na confusão do campo das enfermidades nervosas. Essa correta utilização da Razão e do razoável permitia averiguar as disposições hierárquicas do natural e alcançar um conhecimento preciso. Entender como se dispunham as partes da Natureza foi um ideal básico que, respaldado pelo entrelaçado dos dados registrados pela exploração clínica, sustentou e favoreceu o desenvolvimento de 


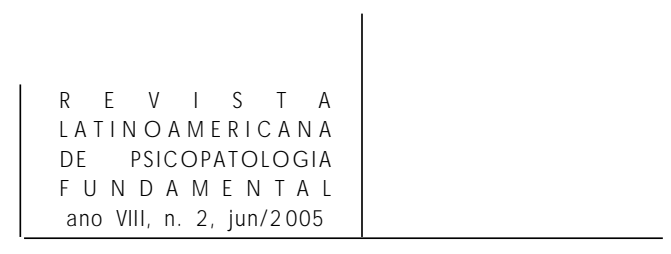

um novo campo epistemológico que foi o da nosologia. O que sucedeu, então, em relação às enfermidades nervosas e aos "vapores”?

\section{Os caracteres da neurose}

Neste texto de crenças, um conhecido e celebrado médico escocês, professor da Universidade de Edimburgo, William Cullen, publicou, em 1777, First Lines in the Practice of Physic, em que afirmava que a histeria, a hipocondria, e todas as afecções do corpo humano de certas características podem chamar-se de nervosas, propondo agrupá-las sob o nome de neurose. "Proponho", dizia, "agrupar sob o título de neurose todas essas afecções preternaturais da sensibilidade e a motricidade nas que a pirexia não constitui uma parte da enfermidade primária; a todas aquelas que não dependem de alterações locais dos órgãos, mas sim de uma afecção geral do sistema nervoso e das potências de onde dependem mais especificamente a sensibilidade e o movimento" (Cullen, 1777, p. 157). ${ }^{1}$ A caracterização baseou-se no registro dos dados empíricos mais relevantes - a preternatural, a sensibilidade, o movimento, a afecção geral do sistema nervoso - com os quais Cullen contribuiu de acordo com as idéias vigentes, uma "classe" ordenadora do panorama das "enfermidades nervosas". Não era esta sua intenção primeira, e anteriormente havia publicado Nosologia ou ordenamento sistemático das enfermidades nas classes, ordens, gêneros e espécies; com os caracteres distintivos de cada descrição dos sistemas de Sauvages, Linneo, Vogel, Sagar e $M c B r i d e$. Este título longo, expondo as intenções do autor da obra, diz às claras que seu procedimento era uma versão particular do more botanico, propugnado pelos naturalistas da Ilustração para tratar sobre a natureza dos seres vivos. O destino do novo termo foi variável: Pinel e Chiaruggi asseguraram seu êxito nos países latinos. Na Grã-Bretanha foi deixado de lado, e os autores românticos alemães usaram-no apenas ocasionalmente. Mas nas mãos do escocês, não nos esqueçamos, abarcava uma ampla área que o correr dos anos delimitou com mais precisão.

De fato, com o vocábulo "neurose" Cullen pretendeu circunscrever a desmedida expansão da idéia de "enfermidade nervosa", buscando diferenciar e ordenar o pouco e dificilmente definido. Para consegui-lo, insistiu nas notas positivas definitórias dos limites desses transtornos ("são afecções gerais preternaturais da sensibilidade e do movimento”) e também nas negativas, separando-as das febres.

1. Descartando-se como parte da afecção primitiva. 
O que significou, pois, qualificar a neurose de "enfermidade geral”? Até fins do século XVII, os médicos haviam conseguido reconhecer inúmeras "espécies mórbidas” - o tifo, a febre tifóide, a nevralgia do trigêmio, o bócio exoftálmico etc. - reconhecendo em numerosos casos o caráter local de certas afecções. Por outro lado, o procedimento anatomopatológico desenvolvido por G. Morgagni havia confirmado a existência de enfermidades que envolviam todo o corpo; mas existiam também afecções gerais que, por sua idiossincrasia, apresentavam sintomas dificilmente agrupáveis, sem a esperada correspondência anatômica. Em conseqüência, "enfermidade geral" foi para Cullen uma afecção estendida a todo o corpo, definitiva por via negativa - "não dependem das alterações locais", escreve -, e especificamente atribuída a alterações do sistema nervoso central. Daí resulta um conceito usado no sentido distributivo. Quais foram os caracteres que levaram em conta para classificar uma afecção como neurose? Recordemos o trecho reproduzido anteriormente em que se referia ao prenatural, à sensibilidade e à motricidade.

\section{O prenatural}

Nas Ilhas Britânicas, as disputas religiosas aplacadas quando do triunfo do puritanismo por obra de Cromwell, não perderam por isso sua vigência. Durante o século XVII, as circunstâncias haviam renovado o interesse pelos problemas teológicos, favorecendo o surgimento de grupos piedosos e promovendo o desenvolvimento de movimentos entusiásticos próprios de um revival religioso. Nos cultos públicos dos Quakers, liderados por Georges Fox, eram freqüentes as condutas inesperadas, as invocações loquazes, as atitudes chamativas, e isso alarmava as autoridades estabelecidas interessadas em manter uma ordem social repressiva; mas, além disso, tais comportamentos se chocavam com o ideal em voga do homem observante das pautas vigentes e medido em suas expressões, proposto pela rede epistêmica. Para o "Ilustrado" - homem racional ou "alma sensível” - os comportamentos entusiásticos eram inconcebíveis, e Shafstesbury punha em sua Carta acerca do entusiasmo, suas conseqüências deploráveis, argüindo que o furor popular pode se chamar pânico quando a raiva das pessoas, como às vezes comprovamos, os põem fora de si, em particular quando se misturam coisas de religião... Porém, além do pânico existe na humanidade outros medos. Também a religião é causa de pânico quando desencadeia um entusiasmo de qualquer natureza como às vezes acontece em situações desfavoráveis, quando os espíritos dos homens estão baixos como acontece nas calamidades públicas, nas perturbações meteorológicas ou dietéticas ou em caso de cataclismos naturais" (Shafstesbury, 1708, p. 107). Existia preocupação e repúdio de exibições desmedidas, que eram condutas desvalorizadas, perigosíssimas em uma época em 


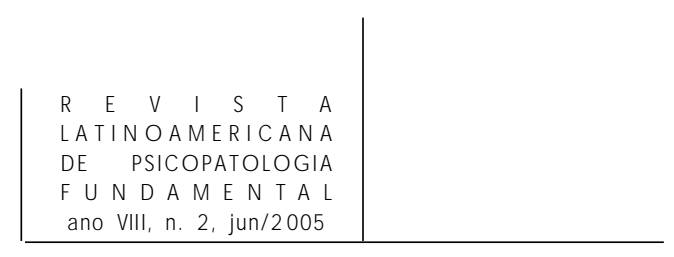

que regia a adesão à ordem convencional e ao bom gosto. Ao tirar o indivíduo de seu habitual, o entusiasmo entrava em colisão com o social, e ainda que nem sempre nocivo, levava tanto ele como o seu grupo a transitar pelo fio da navalha, suscitando serpenteantes e insólitos fenômenos que se chocavam com as convenções culturais. Pior ainda, os "entusiastas" propugnavam a revisão do comportamento social, pelo qual o governo encarcerou Georges Fox em várias ocasiões. Seus seguidores tiveram de se esconder e fugir para pregar a quem se considerava marginais sem religião ou irrecuperáveis, e interromper os sermões dos clérigos adeptos do establishment. Seria absurdo duvidar da sinceridade de Fox, mas não deixa de ser certo que seu comportamento questionador gerou crítica dos sustentadores das vigências sociais, os quais o consideravam um perigoso crítico dos usos e costumes habituais. Ante o questionamento do "estabelecido", o governo optou por qualificá-los, a ele e a seus seguidores, de homens racionais, pouco dignos de crédito e, inclusive, embusteiros. O entusiasta, assegurava, e a excitação de sua imaginação, contagiava o grupo. A fantasia Malebranche a havia chamado de la folle de la maison - companheira inseparável de paixões só aceitável na privacy, incitava à desmesura e punha em perigo a estabilidade social. O entusiasmo e seus signos, a excitação imaginária e passional, os fenômenos insólitos, estranhos e extravagantes, constituíam o campo do preternatural que está por si fora do habitat social. E esta não localização aparece também, admitiu a Ilustração, quando muda o ser das coisas como na enfermidade nervosa. Conseqüentemente, com o qualificativo de "preternatural" o médico do século das Luzes designou o maravilhoso, o insólito, o entusiástico e, basicamente, o inexplicável, pois ainda que tudo isso fosse mais além da ordem natural das coisas não sobrepunha os limites da Natureza. Mas em que pese conhecer seus signos - as contraturas histéricas e o comportamento passional, por exemplo - não se lograva saber o "como" do preternatural, sua aparição desconcertava porque rompia a divisão oitocentista da existência, entre espaço privado e espaço público. As manifestações histéricas ou entusiásticas não respeitavam essa disposição, a qual, para uma mentalidade que aspirava manejar a Natureza, era desconcertante. Foi essa ininteligibilidade, essa anfibiologia e obscuridade que permitiu qualificar as afecções nervosas como preternaturais. Com o propósito de esclarecer o problema, William Cullen argüiu que os signos de tal afecção dependiam da sensibilidade e da motricidade.

\section{A sensibilidade}

Desde Locke e Hume, o naturalismo atribuiu à sensibilidade um papel básico na construção das idéias. Este modo de pensar orientou-se, em sua passagem para o campo médico, para uma consideração empírica das enfermidades, alimentando 
o interesse por explicar a participação do cérebro e dos nervos. No início do século XVIII, Albrecht von Haller (1708-1777) havia abordado este tema sustentando que a irritabilidade, propriedade dos órgãos, em especial dos músculos, era uma propriedade da vida. Seu difundido livro Elemento physilogiae corporis humani apoiava essa tese em observações experimentais, pois ao estimular afetivamente os órgãos mediante a eletricidade estática, cloreto de amônio ou outros irritantes, comprovava resultados similares aos causados pelas impressões sensíveis. Para Haller, esses fatos evidenciavam a existência de uma propriedade específica do sistema nervoso, sua sensibilidade ou capacidade de sentir, que compartilhava com os órgãos relacionados com ele. Essas idéias, amplamente difundidas nos meios acadêmicos, eram admitidas com um geral beneplácito, ao ponto que para a conhecida Enciclopedia o diccionario razonado de las ciências, de las artes y de los ofícios, por la sociedad de la gente de letras, a cargo de Diderot, era algo indiscutível. Dado que "os nervos constituem a base e a essência de todos os órgãos, argumentava Fouquet, está claro que todas as partes do corpo devem estar dotadas de sentimentos ou de sensibilidade e de movimento ou de mobilidade. Apenas as partes puramente mucosas são insensíveis ou imóveis, ou ao menos têm mais de um sentimento ou um movimento tomado do nervo" (Fouquet, s/d). Mas no vocabulário do século XVIII, os vocábulos "sensível", "sentimento", "simpatia", "antipatia" etc., têm significações diferentes da atual, que vão desde a biologia à psicologia, à moral e à estética, o que torna difícil a exata compreensão dos textos: é mister ser prudente para os interceptar. No contexto das idéias cullenianas, o vocábulo sensibilidade remeteu ao conceito de irritabilidade, fenômeno fisiológico em relação direta com os sentimentos, na acepção que Haller havia dado a esses termos.

\section{O movimento}

Os achados de Galileu e Newton fundaram um paradigma e o movimento foi tratado como problema científico. O habitual teria sido considerá-lo desde a filosofia seguindo Aristóteles, que havia descrito suas modalidades - geração, corrupção, aumento, diminuição, alteração e translação - remetendo-as a uma mudança substancial. Afastando-se dessa via, a nova concepção considerava que se tratava de deslocamento local de uma forma provocada pela transmissão de um impulso gerado por algo interno a movido. Como conseqüência, postulou-se um dualismo móvel-motor, que devia ser explicado em função de uma causa eficiente, pois todo movimento remete a um motor que o produz e transmite. No médico, tal modo de pensar promoveu estudos acerca das propriedades da fibra, elemento simples cuja contração origina o movimento. A iatromecânica explicou desse 


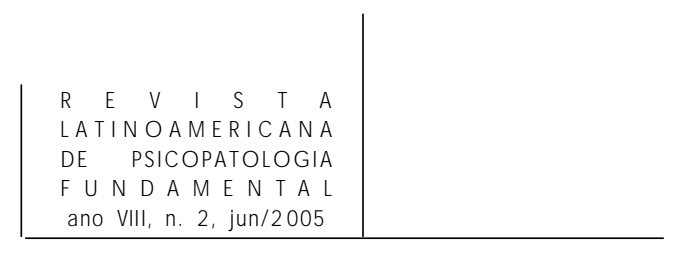

modo o movimento corporal, mas não tardou em cair em descrédito, juntamente com o mecanismo cartesiano, a causa de seu fechado dogmatismo. No entanto, teve indubitáveis acertos, e no tempo de Cullen, se sucedia o movimento como um deslocamento ordenado conduzindo a atos naturais de tradição vital; o médico escocês entendia que os transtornos convulsivos do útero e dos intestinos, a histeria ou a hipocondria deviam-se a alterações nervosas que transtornavam a motilidade corporal.

Suas idéias repetiam sem maiores mudanças as expostas por F. Hoffmann (1680-1740) que havia dado um impulso ao estudo da contração muscular. O "tônus" das fibras do corpo dos seres orgânicos, sua capacidade de encolhimento e relaxamento, ativado por um principio movens ou "éter" - notemos o uso deste vocábulo utilizado pelos partidários dos "vapores”, em uma acepção parecida eram, assegurava, os elementos vitais mais importantes da resistência e coerência do corpo humano. O "sistema" de Hoffmann, deixando de lado os "espíritos animais", postulava em seu lugar a existência de um "fluido nervoso" de igual caráter que circulava aos impulsos da contração e dilatação das fibras da duramater. Por este motivo, dado que as partes sólidas eram capazes de sensibilidade e movimento, a atonia e a hipertonia das fibras originavam estados patológicos perturbadores da circulação do fluido nervoso. A existência de enfermidades espasmódicas causada por esses motivos foi aceita sem discussão por Cullen. No entanto, uma diferença distinguiu o francês do alemão: para este, o "tônus" era uma propriedade imanente na vida animal; para o primeiro foi algo criado pelo sistema nervoso que se reparte pelos órgãos, produzindo espasmos quando se move em excesso, como na histeria e uma atonia quando o faz com lentidão como nas andinamias (Síncopes, clorosis etc.).

Assim caracterizada, a neurose tem quatro tempos - enfermidade geral, preternatural, da sensibilidade e motora - o campo das "enfermidades nervosas" ganhou em concreção, e começou a desempenhar um papel mais definido, pois permitiu sua localização nosológica.

\section{Nosologia}

\section{Inventário e catalogação}

O primeiro passo de um procedimento nosológico consiste em elaborar uma lista ou relação organizada das notas registradas, enumerando-as e agrupando-as em diversos rótulos para depois lhes dar nomes. Ao agir assim, opera-se uma mudança, pois a "coisa concreta" passa a ser "signo" numa lista, mudando de 
estatuto epistemológico. Como conseqüência, o nosólogo opera com abstrações que se combinam entre si segundo um código específico de listagem, dependendo da sua preferência pessoal. Com efeito, ao querer organizar o desorganizado, pode fazê-lo segundo diversos referentes - el cursus morbi -, os sintomas dominantes, o momento da aparição do transtorno etc. - com o qual, ao inventar sintomas patológicos, deixam por sua vez de ser dados concretos - a convulsão, a febre etc. - para serem avaliados como signos abstratos. Graças a isto, o nosólogo do Iluminismo operava num campo ideal em que não iludia a resistência oposta pela realidade, nem sempre coincidente com o conceitualizado; por conseguinte, ao centrar seu interesse na repartição sígnica para modelar o repertório operante necessário, deixava de lado as causas e o sentido. Não há dúvida de que proceder deste modo permitiu aos nosólogos do século XVIII organizarem o confuso panorama patológico herdado, porém esse registro não bastou, pois para que os signos sejam significativos e digam algo, é mister agrupá-los coerentemente entre si. Considerar o valor sígnico dos dados permitiu adotar o more botanico fazendo transitar as afirmações do campo da presença ao da ausência e do concreto ao da representação simbólica. E como um signo é uma abstração, sua distribuição contribuiu decisivamente com a construção de categorias nosológicas. A neurose foi uma delas. Com relação às enfermidades nervosas, Cullen realizou, com efeito, o andamento do signo em seu agrupamento de categorias com o qual agregou ao interesse do "que-é", próprio da tarefa diagnóstica, o relativo "o-que-deveria-ser", deixando de lado a realidade da afecção mesma. Ou seja, para ele uma afeção geral não-febril com signos preternaturais, sensitivos e motores, deveria ser uma neurose, isto é, uma classe nosológica.

O modelo classificatório em voga, o more botanico criado por Linneo, prescrevia a reunião dos signos em espécies, gêneros, ordens e classes, em função de sua semelhança sintomatológica; porém, sua aplicação acrítica conduziu, na medicina, a um agrupamento heteróclito dos transtornos segundo sua manifestação empírica. Tal procedimento buscava, com efeito, estabelecer a correspondência de caracteres entre duas entidades, e ao encontrá-la - ou supondo tê-la encontrado - construía uma abstração capaz de abarcar um número maior de elementos semelhantes. Boissier, Lacroix de Sauvages - respeitado professor de botânica e medicina de Montpellier - contemporâneo de Cullen, observador deste procedimento, sustentava com toda a lógica que "a semelhança das enfermidades particulares se chama espécie; a semelhança das espécies constitui o gênero; e dos gêneros a ordem e das ordens a classe" (Lacroix, 1763, p. 94). Essas afirmações baseavam-se, por um lado, na predominância a respeito do Olhar, sentido capaz de registrar com fidelidade as "semelhanças" ostensivas e, por outro lado, na tentativa de classificar os feitos segundo uma ordem lógica racional. Não obstante, visto que a nosologia operava com os dados variáveis 


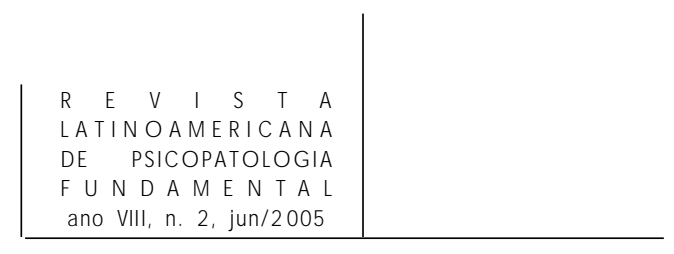

próprios da enfermidade, não alcançou nunca este ideal, em que pese erigir-se num diagrama distributivo de notável saber geometrizante. O âmbito de seu trabalho foi, na realidade, um espaço abstrato onde localizar e registrar o passado, com base no inventário que aspirou a transformar-se num conhecimento capaz de prever o que acontecerá em função de "o-que-deve-ser”. Esta aspiração proclamada por Linneo guiou os médicos do Iluminismo. "A sistematização é para a botânica como o fio de Ariadne sem o qual ela estaria no caos”, havia escrito o célebre naturalista. "Tomem como exemplo uma desconhecida planta das Índias, cujas descrições e figuras um amante de botânica encontra em todos os índices: só a reconheceria por acaso; porém, alguém metódico determinará ipso facto seu gênero, antigo, novo. $\mathrm{O}$ sistema situa as plantas, inclusive aquelas não conhecidas e das quais não pode haver um catálogo" (Linneo, 1793, p. 1). E para inventariar, o já mencionado Boissier de Sauvages chegou a enumerar até 2400 espécies patológicas, agrupadas em 295 gêneros e 10 classes. Nessa armadilha da distribuição ideal caíram muitos nosólogos oitocentistas. Para evitar e preservar a coerência da nosologia sem diluir-se, os cultores de tais idéias buscaram com êxito escasso criar uma sintaxe, respaldando-se no trânsito de dados do signo, do signo à categoria, do passado ao futuro e do concreto ao discursivo. O fracasso deveu-se àqueles que tomaram esses procedimentos ordenadores como descrições da realidade.

Não obstante, suas tentativas contribuíram para a organização de um novo campo epistemológico, possibilitando organizar os signos das enfermidades em categorias distributivas, porém, não o percamos de vista, o ordenado era um conhecimento abstrato e não as notas do transtorno. Se da referência ao signo há um hiato, maior foi o que se mediu entre o signo e a categoria, atentando contra a necessária continuidade ordenadora. Os nosólogos não ignoraram esse inconveniente e trataram de aplainar tal obstáculo introduzindo nos espaços em "branco" do "quadro" nosológico - recordemo-nos do parágrafo transcrito de Linneo agrupamentos heurísticos originários das similaridades superficiais. Mas seguindo os passos de Locke e Condillac, a nosologia reduzida a seu campo comprovado sensivelmente se transformou numa construção ideológica em função de um referente estranho ao "ordenado". A intenção de Pinel de seguir tal caminho colocou-o em evidência. Porém, não nos adiantemos e olhemos a nosologia culleriana, onde quatro classes - pirexias, caquexias, neuroses e afecções locais - distribuem-se em outras quatro ordens - comata, adynamiae, spasmi, e vesaniae -, diversos em gêneros e espécies. $\mathrm{O}$ que sucede nela com a classe neurose?

O agrupamento de Cullen pouco nos diz do ponto de vista terapêutico e assistencial, e alguma coisa do ponto de vista cognitivo. Por que Cullen agrupou a histeria junto aos tétanos, trismos, epilepsias e palpitações, afecções em que apareciam espasmos e violentas contrações musculares prolongadas? Salta à vista 


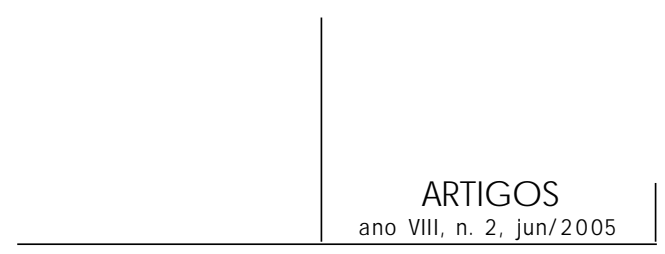

que, por basear-se na semelhança sintomática, constituiu a ordem dos espasmos. Da mesma maneira, valorizando a semelhança, agrupou outros transtornos "nervosos", com alterações motoras e de sensibilidade, na ordem dos comas, adinamias e vesânias, criando uma classe - resultado da abstração - capaz de abarcá-los. E como referente comum usou a enfermidade nervosa, criou um vocábulo, neurose, para denominar essa abstração nosológica. Tal conclusão satisfez as expectativas dos científicos de seu tempo, porque ao obter novos dados é necessária sua incorporação de tal forma que a totalidade conceitual possa tornar-se mais completa, consistente e útil. Fiel ao princípio, o professor escocês "situou" os dados recolhidos num quadro abstrato e edificou categorias dependentes dos modos funcionais ou anatômicos de aparecimento dos signos patológicos. O paradigma vigente newtoniano e sua adesão à tese de F. Hoffmann - um dos grandes sistemáticos do Iluminismo que atribuía uma função, a respeito da construção e relaxação dos “sólidos” um papel decisivo em relação ao sistema nervoso - proporcionou-lhe o embasamento científico necessário. Em que pese seu mérito esclarecedor, seu intento falhou porque para que seja válido um ensaio ordenador - e a nosologia foi uma de suas modalidades - a distribuição dos elementos que o integram há de ser homogênea e sem mudança de níveis epistemológicos, pois importa mais sua funcionalidade do que o modelo usado. A classe neurose, fruto do propósito de construir uma ordem médica ideal, abstrata, intelectual e hierárquica, respaldada num continuum distributivo das “enfermidades nervosas”, não cumpriu essas condições, pelo qual foi recortandose cada vez mais sua abrangência... Para o médico, o novo campo epistemológico ofereceu um cômodo "lugar” científico para situar o conhecido, que desempenhou o papel de contexto para arrolar um procedimento apto a explicar o comprovado e progredir em seu conhecimento. O preço pago foi limitar o vôo imaginário do pensamento médico.

No entanto, a nosologia não foi somente um inventariar e um catalogar, pois teve, ademais, de denominar o agrupado, gerar uma nomenclatura. Vamos chegar a esse ponto.

\section{Denominação e nomenclatura}

Ao engendrar um campo epistemológico próprio, a nosologia precisou de um vocabulário apropriado e específico para designar seus rubros distributivos. Graças ao seu velho prestígio, as línguas clássicas, o grego e o latim, idiomas de uso consagrado nos meios acadêmicos, proporcionaram o material necessário. Vimos acima como, para denominar a classe onde agrupou os espasmos, comas, adinamias e vesânias que teriam, em comum, ser “enfermidades nervosas”. 


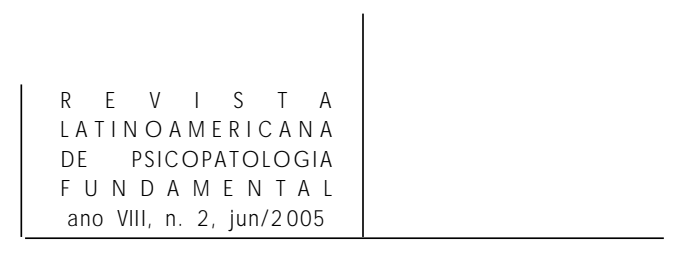

"Quase todas as enfermidades do corpo consideradas sob certo aspecto podiam chamar-se nervosas”, escreveu, "porém de nada serviria uma denominação tão genérica e, por outro lado, não me parece conveniente limitar este vocábulo aplicando-o de modo vago e inexato às afecções histéricas e hipocondríacas que, por si, não se podem definir com bastante exatidão" (ibid., p. 68). Com o novo termo, Cullen tentou, dizíamos, circunscrever a vaguidão conceitual da idéia de "enfermidade nervosa”, dando-lhe uma realidade semântica e classificatória. Para consegui-lo, respaldou-se na crença, tal como se admitia em seu tempo, de que só há uma consciência possível do geral, e na necessidade de nomear os conhecimentos segundo um código exato e apropriado para não desvirtuá-los. E como era aceito que o ordenamento do vocabulário facilita o entendimento, deu a cada coisa um nome apropriado que somente a ela convinha, sem incluir coisas diferentes nem dar nomes diferentes à mesma coisa. Por outro lado, acreditava o Iluminismo que o ordenamento preciso e correto dos nomes correspondia ao das coisas, o que gerou uma intensa preocupação em conseguir uma denominação ordenadora estrita e específica. A clareza e precisão de uma nomenclatura foram então de especial importância, porque se for difusa e inerte suscitará idéias diferentes causando um equívoco. O vocábulo "neurose”, neologismo em que participava um nome de uso habitual nos meios sociais e científicos, e ao qual se adicionou uma terminação grega, conquistou prestígio com facilidade. Tempos antes, o mesmo Cullen, com intenções análogas, havia usado o vocábulo neuropathia, mas sua impressão e parca eufonia haviam feito com que o abandonasse. No entanto, se uma denominação bem precisa determina o alcance do que é nomeado, reduz o halo conotativo e imaginário necessário para assegurarlhe maior profundidade. O termo "vapores", recordemos, punha em jogo um imaginário sutil, volátil, etéreo; os vocábulos spleen e nostalgia traziam consigo imagens de profunda ressonância psíquica, mas "neurose”, palavra vinda de um vocabulário científico, carecia dessas virtudes, o que impediu a expansão de sua significação. E se cada vocábulo aspira ser núcleo de uma metáfora, "neurose", pelo contrário, deteve-se no intento de ser uma denominação "pura", exata e precisa. A sistematização do vocabulário, afirmava o respeitável Linneo em sua Filosofia botânica, livro muitas vezes reeditado, era o fio condutor para o conhecimento ordenado e "a ciência natural tem como guia o conhecimento da nomenclatura metódica e sistemática dos corpos naturais: é o fio de Ariadne sem o qual não é possível sair sozinhos e seguros do dédalo da natureza” (Linneo, 1788, p. 5). Contudo, em que pese a predominância desse ideal, os médicos do século XVIII não deixaram de ser sensíveis a suas deficiências, daí por que o temor da imprecisão levou-os a criar neologismos estrambóticos para resistir à possibilidade de originar uma brecha nesse edifício racional.

Não obstante, o fio de Ariadne que assegurou o êxito ao neologismo 
categorizador culleriano foi seu ordenamento lógico, more botanico, dentro da nomenclatura. Ao construir a "classe" da neurose, o escocês Cullen superou as contradições implícitas na patologia de seu tempo, impulsionando uma colocação exata e não-contraditória em que cada afecção teve um lugar hierárquico em seu fichário. O preço foi a imobilização dessa ordem. Com efeito, no sistema de denominações de uma nomenclatura, conjunto com propriedades diferentes das de seus integrantes, a identidade concebida para cada nome mantém relações solidárias com os substantivos restantes num círculo fechado, homogêneo e isotrópico; mas ao existir neste circuito hierarquias entre seus componentes, as denominações nomeiam também os diferentes graus de poder. Os integrantes de um regimento - oficiais, sub-oficiais, soldados - são militares, mas se diferem em relação ao mando e ao poder. De maneira análoga a classe neurose foi patográficamente [?] mais abrangente e poderosa do que a ordem vesania - esta, mais que o gênero dementia, e este, mais que a espécie mórbida de dementia senilis; inversamente, segundo se vá subindo nessa escala nosológica, a denominação remetia a algo mais geral, universal e abstrato. Isto impôs a necessidade de usar denominações com igual caráter de universalidade e abstração. O valor nosológico respaldou-se assim na classificação daquilo que nomeava, situava e prestigiava, distinguindo-o de outras afecções e divisões num esquema prévio. E assim foi construindo-se uma realidade abstrata metadiscursiva que repousou na crença sobre a existência de um continuum natural. Essa "construção" de uma classe nosológica foi o germe, como veremos, para outros desdobramentos e diferenciações.

\section{Referências}

CulLen, W. First lines of the practice of physic. Edimburgo: Elliot, 1777. t. I, p. 157.

Fouquet. Sensibilidade-sentimento em Encyclopédie. Paris, s/d.

LaCroix de Sauvages, B. Nosologie botanique. Amsterdam, 1763. t. I, p. 94.

LAING Entralgo, P. Historia de la medicina. Madrid: Salvat. t. V, p. 68.

LinNEo. Système de la nature. Bruselas, 1793. t. I, p. 1.

Philosophie botanique. Paris, 1788. p. 5.

Shafstesbury, A. (1708). Letter concerning enthusiasm. In: Gusdorf, G. Les sciences humaines et la pensée occidentale. 14 v. Paris: Payot, 1972. t. V, p. 107. 


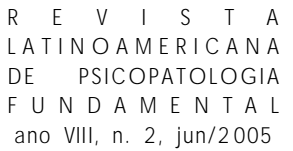

\section{Resumos}

El surgimiento de la idea de “enfermedad nerviosa” proporcionó a la psiquiatría del iluminismo la posibilidad de desenvolverse en una dirección mas concreta y positiva. No obstante, el campo era todavía difuso, si bien que la obra de los nosólogos iba organizando y discriminando afecciones con perfiles más claros. La intención de llevar tal clareza para el terreno de las enfermedades nerviosas llevó a W. Cullen a agrupar esos trastornos en la clase "neurosis”. Se utilizó para eso del procedimiento nosológico acepto en la época.

Palabras claves: Historia de la psiquiatría, nosología, neurosis

L'apparition de la notion de "infirmité nerveuse” permit à la psychiatrie de l'Illuminisme de se développer dans une direction plus concrète et positive. Mais ce champ était encore diffus, encore que l'oeuvre des nosologistes ait organisé et discriminé les affections sous la forme de profils mieux définis. L'intention d'amener cette clarté sur le terrain des infirmités nerveuses amena $W$. Cullen à regrouper ces troubles dans la classe des "névroses". Pour cela il utilisa le procédé nosologique en vogue à cette époque.

Mots clés: Histoire de la psychiatrie, nosologie, névrose

The apparition of the concept of "nervous alteration" in the XVII century, offers to psychiatry the possibility of a better and more solid development. Based on the Linneus idea of discrimination, description and classifications, nosologist constructed several ordenations of patology. One of them, $W$. Cullen, using the nosologic method created the term "neurosis" to clarify these ideas in order to nervous alterations.

Key words: History of psichiatry, nosology, neurosis 